\title{
Reliability of non-lethal surveillance methods for detecting ranavirus infection
}

\author{
Matthew J. Gray ${ }^{1, *}$, Debra L. Miller ${ }^{2,3}$, Jason T. Hoverman ${ }^{1,4}$ \\ ${ }^{1}$ University of Tennessee, Center for Wildlife Health, Department of Forestry, Wildlife and Fisheries, \\ 274 Ellington Plant Sciences Building, Knoxville, Tennessee 37996-4563, USA \\ ${ }^{2}$ University of Georgia, College of Veterinary Medicine, Veterinary Diagnostic and Investigational Laboratory, \\ 43 Brighton Road, Tifton, Georgia 31793, USA \\ ${ }^{3}$ Present address: University of Tennessee, Center for Wildlife Health and Department of Biomedical and \\ Diagnostic Sciences, College of Veterinary Medicine, Knoxville, Tennessee 37996-4563, USA
}

${ }^{4}$ Present address: Department of Forestry and Natural Resources, Purdue University, 195 Marsteller Street, West Lafayette Indiana 47907-2033, USA

\begin{abstract}
Ranaviruses have been identified as the etiologic agent in many amphibian die-offs across the globe. Polymerase chain reaction (PCR) is commonly used to detect ranavirus infection in amphibian hosts, but the test results may vary between tissue samples obtained by lethal and non-lethal procedures. Testing liver samples for infection is a common lethal sampling technique to estimate ranavirus prevalence because the pathogen often targets this organ and the liver is easy to identify and collect. However, tail clips or swabs may be more practicable for ranavirus surveillance programs compared with collecting and euthanizing animals, especially for uncommon species. Using PCR results from liver samples for comparison, we defined false-positive test results as occurrences when a non-lethal technique indicated positive but the liver sample was negative. Similarly, we defined false-negative test results as occurrences when a non-lethal technique was negative but the liver sample was positive. Using these decision rules, we estimated false-negative and false-positive rates for tail clips and swabs. Our study was conducted in a controlled facility using American bullfrog Lithobates catesbeianus tadpoles; false-positive and falsenegative rates were estimated after different periods of time following exposure to ranavirus. False-negative and false-positive rates were 20 and $6 \%$, respectively, for tail samples, and 22 and $12 \%$, respectively, for swabs. False-negative rates were constant over time, but false-positive rates decreased with post-exposure duration. Our results suggest that non-lethal sampling techniques can be useful for ranavirus surveillance, although the prevalence of infection may be underestimated when compared to results obtained with liver samples.
\end{abstract}

KEY WORDS: Iridovirus $\cdot$ Ranavirus $\cdot$ Molecular technique $\cdot$ PCR $\cdot$ Sampling $\cdot$ Surveillance

\section{INTRODUCTION}

Amphibians are declining globally (Stuart et al. 2004), and emerging infectious diseases are responsible for some of these declines (Wake \& Vredenburg 2008). A group of viruses in the genus Ranavirus (family Iridoviridae) have caused widespread die-offs of amphibians in wild populations (Gray et al. 2009a). Most of these reports have been associated with amphibian larvae (Miller et al. 2011), although dieoffs in adult frogs and newts have occurred in Europe (Cunningham et al. 2007, Balseiro et al. 2010). Given the threat posed by ranaviruses to amphibians and the possibility of transporting the virus during commerce, ranaviral disease was listed as notifiable by the World Organization for Animal Health (OIE, Schloegel et al. 2009). The OIE guidelines require testing of commercially traded amphibians prior to 
shipment in order to verify that they are not infected with ranavirus. Also, in order to better understand the threat that ranaviruses pose to native amphibians, surveillance for this pathogen is becoming more widespread in wild populations (e.g. Gray et al. 2007, 2009b, Greer et al. 2009, Hoverman et al. 2012). Given the increased need to test amphibians for ranavirus infection, the usefulness of non-lethal sampling techniques needs to be determined.

Common non-lethal techniques for pathogen testing include tail or toe clips and swabs of the oral cavity, cloaca and skin (Brunner et al. 2004, Kriger et al. 2006, St-Amour \& Lesbarrères 2007, Driskell et al. 2009, Gray et al. 2009b). Testing amphibians for infection using non-lethal techniques has several advantages - including, presumably, a low impact on wild or captive populations, the possibility of repeat sampling of the same individual, and generally, a lower cost compared to full necropsies of euthanized animals (Greer \& Collins 2007, St-Amour \& Lesbarrères 2007, Green et al. 2010). These advantages are particularly useful when monitoring infection in uncommon species. Polymerase chain reaction (PCR) is commonly used to test for the occurrence of ranavirus DNA in amphibians (Brunner et al. 2004, Pallister et al. 2007). However, PCR results can depend on the amount of viral DNA circulating in the amphibian host and the type of tissue tested (Greer \& Collins 2007, St-Amour \& Lesbarrères 2007). Ranaviruses are known to target the liver, especially in larval amphibians (Docherty et al. 2003, Robert et al. 2005, Miller et al. 2009), and necrosis within this organ can cause morbidity and mortality (Miller et al. 2007, 2008). Thus, liver samples are commonly used when testing for ranavirus infection (St-Amour \& Lesbarrères 2007, Green et al. 2010). Only a few studies have investigated whether PCR test results for ranavirus infection are similar for samples obtained by lethal and non-lethal techniques (Greer \& Collins 2007, St-Amour \& Lesbarrères 2007), and no studies have compared test results for more than one non-lethal technique. Our objective was to compare the PCR test results obtained with swab, tail clip and liver samples from tadpoles exposed to ranavirus.

\section{MATERIALS AND METHODS}

We obtained Frog virus 3 (FV3) from V. Gregory Chinchar of the University of Mississippi; this virus was originally cultured from the northern leopard frog Lithobates pipiens in the 1960s (Granoff et al. 1965). Virus culturing was done at the University of
Georgia Veterinary Diagnostic and Investigational Laboratory (VDIL); details of these methods can be found in Hoverman et al. (2010). Titered virus was sent overnight to the University of Tennessee and stored at $-80^{\circ} \mathrm{C}$ until used in the experiment.

We conducted our experiment in a controlled laboratory of the Joe Johnson Animal Research and Teaching Unit (JARTU) at the University of Tennessee. We used American bullfrog Lithobates catesbeianus tadpoles for our study because this species is known to carry sublethal infections of ranavirus (Miller et al. 2009). We purchased tadpoles from a ranaculture facility in southern Georgia (Miller et al. 2007) and transported them overnight to the University of Tennessee. All individuals were tail clipped initially to test for ranavirus infection using quantitative PCR (qPCR) (see below), considering that ranavirus outbreaks have occurred previously at this ranaculture facility (Miller et al. 2007). The preexperiment prevalence of ranavirus was $57 \%$ in the tadpoles. We previously identified the ranavirus at the Georgia ranaculture facility as an FV3-like isolate (GenBank accession no. EF101698; Miller et al. 2007).

Our experimental units $(\mathrm{n}=96)$ consisted of tanks, each with a capacity of 751 and containing 401 of dechlorinated water. An individual tadpole, between Gosner (1960) stages 26 and 30, was randomly assigned to each experimental unit and fed a daily ration of 2 pellets of commercial rabbit chow (Purina Mills). The experiment was conducted under standard laboratory conditions $\left(23^{\circ} \mathrm{C}\right.$ and a $12 \mathrm{~h}$ day: $12 \mathrm{~h}$ night photoperiod). Water was not changed in the tanks during the course of the experiment. We orally inoculated half of the tadpoles with $10^{6}$ plaque-forming units of FV3 suspended in $10 \mu \mathrm{l}$ of Eagle's minimum essential medium (MEM). The remaining tadpoles, orally inoculated with $10 \mu \mathrm{l}$ of MEM, served as a treatment control. Given that the pre-experiment tail clippings were not tested for ranavirus infection (by qPCR) until after the experiment had been completed, pre-infected tadpoles were unknowingly assigned to both the control and experimental treatments. We randomly selected and euthanized 16 tadpoles ( $\mathrm{n}=8$ per treatment) at 3, 7, 14, 21, 28 and $35 \mathrm{~d}$ post-inoculation (PI). Tadpoles were euthanized by transdermal exposure to benzocaine hydrochloride in a water bath. Fresh benzocaine and a new container were used for each tadpole. Following euthanasia, we swabbed the oral cavity first then the cloaca 5 times each using BBL ${ }^{\mathrm{TM}}$ culture swabs (Becton, Dickinson, and Company) and cut a ca. $10 \mathrm{~mm}$ section from the distal end of the tail using sterilized 
scissors. We made an incision mid-ventrally in each tadpole and collected about half of the liver using a sterile scalpel blade. We used different instruments and changed disposable gloves between tadpoles to prevent cross-contamination. We placed tail clips, swabs and liver tissue in separate microcentrifuge tubes and stored them at $-80^{\circ} \mathrm{C}$. All procedures followed approved University of Tennessee Institutional Animal Care and Use Committee (IACUC) protocol \#1678 and University of Georgia IACUC protocol \#A2007-10167.

Sample testing was performed following standard operating procedures of the University of Georgia VDIL. In brief, we extracted genomic DNA using a DNeasy Blood and Tissue Kit (Qiagen). We used the Qubit $^{\mathrm{TM}}$ fluorometer and the Quant-iT ${ }^{\mathrm{TM}}$ dsDNA BR Assay Kit (Invitrogen) to quantify the concentration of genomic DNA in the samples and to standardize the likelihood of virus detection among animals. We performed real-time qPCR to test for ranavirus infection following Picco et al. (2007). The PCR mixture included: $12.5 \mu$ of TaqMan Universal PCR Master Mix (Applied Biosystems), $1.5 \mu \mathrm{l}$ of each primer at

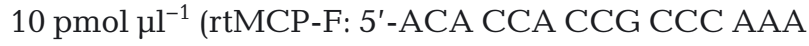
AGT AC-3'; rtMCP-R: 5'-CCG TTC ATG ATG CGG ATA ATG-3'), and $0.15 \mu \mathrm{l}$ of rT-mcp-probe (5'-CCT CAT CGT TCT GGC CAT CAA CCA-3'). Based on the values obtained from the Qubit ${ }^{\mathrm{TM}}$ fluorometer, we added $1 \mu \mathrm{g}$ of template DNA and DNA-grade water to a final volume of $25 \mu$ l. The qPCR was performed using a SmartCycler system (Cepheid). The cycle threshold, $\left(C_{\mathrm{T}}\right)$ value for the qPCR was set at a fluorescence value of 30 based on previous instrument optimization with known positive and negative controls. The qPCR was run in duplicate, with 2 positive controls (cultured virus and known positive tadpole) and 2 negative controls (water and known negative animal). We have demonstrated that this qPCR protocol is effective in detecting FV3 and the FV3-like isolates from the Georgia ranaculture facility (Hoverman et al. 2010). A sample was declared positive when the $C_{\mathrm{T}}$ was $<30$ in 2 independent runs. For our samples, $C_{\mathrm{T}}=18$ to 29 for positive samples.

We calculated 3 proportions separately for tails and swabs based on their agreement with liver qPCR results (St-Amour \& Lesbarrères 2007): (1) test results identical, (2) negative results when the liver was positive (i.e. false negatives), and (3) positive results when the liver was negative (i.e. false positives). As in St-Amour \& Lesbarrères (2007), we used the liver for comparison because ranavirus often targets this organ and it is easy to identify and sample. Ranaviruses are known to infect many other organs, including skin, kidney, intestines and the nervous system (Miller et al. 2011); thus, inferences from our results are limited to the liver. The results from different target organs may also differ depending on the amount of time between ranavirus exposure and testing (Robert et al. 2005). In Xenopus laevis, the liver becomes infected after the kidneys (Robert et al. 2005) so that liver infection may be indicative of multi-systemic infection. Inasmuch as target organs may differ for different types of virus and host species, our results may be limited to American bullfrog tadpoles and the isolates used in our study. Also, a positive qPCR result indicated that ranavirus DNA was present (Green et al. 2010); however, distinction between active and quiescent infections (Morales et al. 2010) could not be made. Other techniques, e.g. immunohistochemistry, in situ hybridization and virus isolation (Green et al. 2010), can be used to determine the presence of ranavirus infections but were not evaluated in this study.

We compared the proportion of test results that were identical with the proportion of false-positive and false-negative tests using a Mantel-Haenszel test (Stokes et al. 2000) because these proportions were not independent. The accuracy of PCR results from non-lethal techniques may vary with the stage of infection (Greer \& Collins 2007); thus, we also compared false-negative and false-positive rates separately on different days PI. We used logistic regression analysis for these tests (Milton \& Arnold 1995) because these proportions were independent given that different tadpoles were euthanized on different days PI. For these analyses we included time and exposure treatment (control vs. intentional exposure to FV3), and their interaction in the logistic regression model, to demonstrate that the exposure treatment had no effect on interpreting false-positive and false-negative results. We also reported infection rates on different days PI for qualitative comparison with false-test results. It has been hypothesized that false-test results from samples obtained by nonlethal methods will decrease as prevalence increases (Greer \& Collins 2007). We performed all analyses using the $\mathrm{SAS}^{\circledR}$ system at $\alpha=0.05$ (Stokes et al. 2000).

\section{RESULTS}

Test results from tail clips and swabs were identical with the results from the liver for 74 and $66 \%$ of samples, respectively (Fig. 1). False-negative and falsepositive rates were 20 and $6 \%$, respectively, for tail 


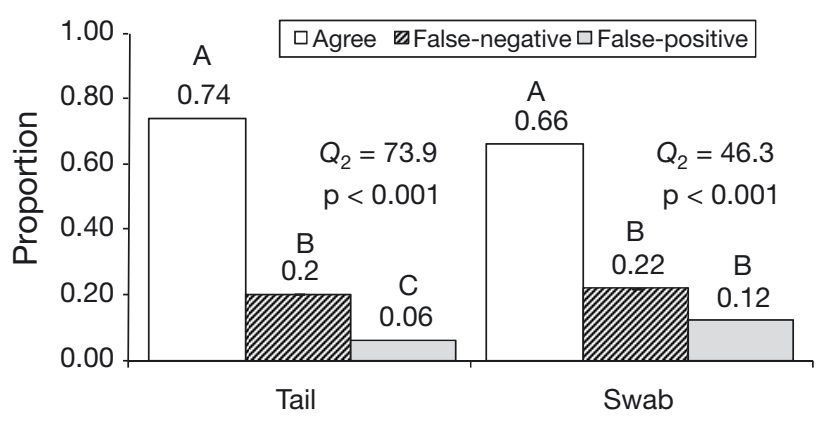

Fig. 1. Lithobates catesbeianus infected by ranavirus. Proportion of quantitative polymerase chain reaction (qPCR) test results for ranavirus from tail clips and swabs that were identical to the results from liver samples (agree), negative when the liver sample was positive (false-negative), and positive when the liver sample was negative (false-positive) across all sample dates $(\mathrm{n}=96)$. Bars for tail clips and swabs with unlike letters are significantly different by the MantelHaenszel Q-test

samples, and 22 and $12 \%$ for swabs (Fig. 1). Falsenegative rates for tail clips and swabs did not differ among days PI (Table 1). False-positive rates for swabs and tail clips decreased with number of days PI, although this relationship was statistically significant for swabs only (Table 1). No differences existed in false-positive and false-negative test results between exposure treatments $\left(\chi^{2}{ }_{(1)}<0.01, \mathrm{p}>0.95\right)$, and this effect did not interact with the number of days PI $\left(\chi^{2}{ }_{(5)}<1.79, \mathrm{p}>0.88\right)$. Thus, given that the trends of false-positive and false-negative rates were consistent between exposure treatments among time periods, we presented the results for cumulative days PI in Table 1, which was the only effect in the logistic regression analysis that was significant.

Ranaviruses prevalence in tadpoles from the Georgia ranaculture facility prior to inoculation was $57 \%$. Following inoculation of half of the tadpoles with
FV3, overall prevalence increased to $70 \%$ at $7 \mathrm{~d}$ PI but decreased thereafter to $13 \%$ at $35 \mathrm{~d}$ PI (Table 1). Qualitatively, a positive relationship existed between false-positive rates and the prevalence of ranaviruses (Table 1). No tadpoles died during the study.

\section{DISCUSSION}

Results of tests by PCR on tail clips and swabs were different from the results obtained from the liver for 26 and $34 \%$ of samples, respectively. These rates of disagreement are higher than those reported in previous studies. On average, results from $15 \%$ of tail clips disagreed with the PCR results from whole metamorphosed salamanders Ambystoma mavortium stebbinsi that were tested for ranavirus (Greer \& Collins 2007). Ten percent of toe clips from adult green frogs Lithobates clamitans gave PCR test results that were different from those obtained with liver samples (St-Amour \& Lesbarrères 2007). In our study, the majority of test disagreements were falsenegative tests $(20 \%$ for tail clips, $22 \%$ for swabs). False-negative tests can occur when the number of virions circulating in the host's tissues is low, or few virions are shed (Greer \& Collins 2007). We hypothesize that the higher false-negative rates in our experiment, compared to the results of Greer \& Collins (2007), were related to host susceptibility. We used American bullfrogs which have low susceptibility to FV3 infection (Miller et al. 2009, Hoverman et al. 2011), whereas larval Sonoran tiger salamanders are highly susceptible to ranavirus (Collins et al. 2004). Thus, low-grade infections in the liver of the bullfrog tadpoles used in our study may not have been detected accurately with tail clips or swabs due to few circulating virions.

For tail clips and swabs, the num-

Table 1. Proportion of false-negative and false-positive quantitative polymerase chain reaction (qPCR) results for ranavirus in tail clips and swabs of the American bullfrog Lithobates catesbeianus tadpoles using non-lethal techniques, and the prevalence of ranavirus in tadpoles at 6 different durations post-inoculation. False negative $=$ negative when the liver sample was positive; false positive $=$ positive when the liver sample was negative. Cumulative days post-inoculation: number of days following oral inoculation of either ranavirus or Eagle's minimum essential medium (MEM) ( $\mathrm{n}=16$ per duration; 8 per oral inoculation treatment)

\begin{tabular}{|c|c|c|c|c|c|c|c|c|c|}
\hline \multirow{2}{*}{$\begin{array}{l}\text { PCR test } \\
\text { result }\end{array}$} & \multirow{2}{*}{$\begin{array}{l}\text { Type of } \\
\text { sample }\end{array}$} & \multicolumn{6}{|c|}{ Cumulative days post-inoculation } & \multirow[t]{2}{*}{$\chi^{2}{ }_{(5)}$} & \multirow[t]{2}{*}{$\mathrm{p}$} \\
\hline & & 3 & 7 & 14 & 21 & 28 & 35 & & \\
\hline \multirow[t]{2}{*}{ False negative } & Tail & 0.31 & 0.13 & 0.31 & 0.13 & 0.25 & 0.06 & 5.84 & 0.32 \\
\hline & Swab & 0.13 & 0.25 & 0.25 & 0.31 & 0.25 & 0.13 & 2.74 & 0.74 \\
\hline \multirow[t]{2}{*}{ False positive } & Tail & 0.13 & 0.19 & 0 & 0 & 0 & 0.06 & 8.53 & 0.13 \\
\hline & Swab & 0.38 & 0.25 & 0.06 & 0 & 0 & 0.06 & 17.1 & 0.004 \\
\hline Prevalence & Liver & 0.63 & 0.69 & 0.38 & 0.31 & 0.25 & 0.13 & 16.1 & 0.007 \\
\hline
\end{tabular}
with increasing time PI, and was positively related with liver infection. Although the mechanism behind false-positive test results is unknown, it may have been related to active infections in other organs. In Xenopus laevis, the liver often becomes infected after other organs (Robert et al. 2005). It also is possible that qPCR detected quiescent ranavirus in circulating macrophages (Morales et al. 2010), although it is unclear why infected macrophages would not have been 
present in the liver as well. It is unlikely that sample contamination occurred given our sterilization protocol. Whether or not the liver should be used as a standard for qPCR testing remains to be determined. We encourage future studies to test multiple types of cell and to compare infection rates in tissue samples obtained by non-lethal procedures.

The trend of decreasing ranavirus prevalence over time suggests that bullfrog tadpoles have the capability of clearing this pathogen, which is the first direct evidence for this species. Clearing of ranavirus infections has been reported in Xenopus laevis (Gantress et al. 2003). Given that bullfrog tadpoles appear to be able to live with sublethal infections (Miller et al. 2009), this species may be an important reservoir for this pathogen, which has been previously suggested (Gray et al. 2007).

Our study demonstrated that non-lethal techniques can be useful for ranavirus surveillance in tadpole populations; however, estimates of infection prevalence may vary depending on sampling technique. Given that we documented rates of 20 and $22 \%$ falsenegatives for tail and swab samples, respectively, these non-lethal techniques may underestimate the prevalence of infection when compared to liver samples. Thus, when feasible, we recommend lethal sampling and full necropsies, as this will allow more reliable detection of ranavirus as well as concurrent infections with other pathogens (Miller et al. 2008). Additionally, histology from euthanized animals allows documentation of organ damage, including subtle changes associated with sublethal infections. Collectively, this information will help to elucidate the impact of ranaviruses on amphibian host species. Green et al. (2010) and Pessier \& Mendelson (2010) provide recommendations on procedures for lethal and non-lethal collection of samples for ranavirus testing.

Acknowledgements. This study was supported by the University of Tennessee Institute of Agriculture (UTIA), the University of Georgia Veterinary Diagnostic and Investigational Laboratory (VDIL) in Tifton, and the Association of Reptilian and Amphibian Veterinarians. We thank L. Whittington of the VDIL for assistance with qPCR, and J. Hodges, B. Simpson, M. Campbell, and R. Long of the UTIA JARTU facility for laboratory resources and assistance with experiment set up. We thank several anonymous referees for comments on previous versions of our manuscript.

\section{LITERATURE CITED}

Balseiro A, Dalton KP, Del Cerro A, Márquez I, Parra F, Prieto JM, Casais R (2010) Outbreak of common midwife toad virus in alpine newts (Mesotriton alpestris cyreni) and common midwife toads (Alytes obstetricans) in
Northern Spain: Comparative pathological study of an emerging ranavirus. Vet J 186:256-258

Brunner JL, Schock DM, Davidson EW, Collins JP (2004) Intraspecific reservoirs: complex life history and the persistence of a lethal ranavirus. Ecology 85:560-566

Collins JP, Brunner JL, Jancovich JK, Schock DM (2004) A model host-pathogen system for studying infectious disease dynamics in amphibians: tiger salamanders (Ambystoma tigrinum) and Ambystoma tigrinum virus. Herpetol J 14:195-200

Cunningham AA, Hyatt AD, Russell P, Bennett PM (2007) Emerging epidemic diseases of frogs in Britain are dependent on the source of ranavirus agent and the route of exposure. Epidemiol Infect 135:1200-1212

> Docherty DE, Meteyer CU, Wang J, Mao J, Case S, Chinchar GD (2003) Diagnostic and molecular evaluation of three iridovirus-associated salamander mortality events. J Wildl Dis 39:556-566

Driskell EA, Miller DL, Swist SL, Gyimesi ZS (2009) PCR detection of ranavirus in adult anurans from the Louisville Zoological Garden. J Zoo Wildl Med 40: 559-563

> Gantress J, Maniero GD, Cohen N, Robert J (2003) Development and characterization of a model system to study amphibian immune responses to iridoviruses. Virology 311:254-262

Gosner KL (1960) A simplified table for staging anuran embryos and larvae with notes and identification. Herpetologica 16:183-190

Granoff A, Came PE, Rafferty KA (1965) The isolation and properties of viruses from Rana pipiens: their possible relationship to the renal adenocarcinoma of the leopard frog. Ann NY Acad Sci 126:237-255

Gray MJ, Miller DL, Schmutzer AC, Baldwin CA (2007) Frog virus 3 prevalence in tadpole populations inhabiting cattle-access and non-access wetlands in Tennessee, USA. Dis Aquat Org 77:97-103

> Gray MJ, Miller DL, Hoverman JT (2009a) Ecology and pathology of amphibian ranaviruses. Dis Aquat Org 87: 243-266

Gray MJ, Miller DL, Hoverman JT (2009b) First report of ranavirus infecting lungless salamanders. Herpetol Rev 40:316-319

Green DE, Gray MJ, Miller DL (2010) Disease monitoring and biosecurity. In: Dodd CK (ed) Amphibian ecology and conservation: a handbook of techniques. Oxford University Press, Oxford, p 481-505

> Greer AL, Collins JP (2007) Sensitivity of a diagnostic test for amphibian ranavinus varies with sampling protocol. J Wildl Dis 43:525-532

> Greer AL, Brunner JL, Collins JP (2009) Spatial and temporal patterns of Ambystoma tigrinum virus (ATV) prevalence in tiger salamanders Ambystoma tigrinum nebulosum. Dis Aquat Org 85:1-6

- Hoverman JT, Gray MJ, Miller DL (2010) Anuran susceptibilities to ranaviruses: role of species identity, exposure route, and a novel virus isolate. Dis Aquat Org 89:97-107

$>$ Hoverman JT, Gray MJ, Haislip NA, Miller DL (2011) Phylogeny, life history, and ecology contribute to differences in amphibian susceptibility to ranaviruses. EcoHealth 8:301-319

Hoverman JT, Gray MJ, Miller DL, Haislip NA (2012) Widespread occurrence of ranavirus in pond-breeding amphibian populations. EcoHealth (in press) doi: 10.1007/ s10393-011-0731-9 
Kriger KM, Hines HB, Hyatt AD, Boyle DG, Hero JM (2006) Techniques for detecting chytridiomycosis in wild frogs: comparing histology with real-time Taqman PCR. Dis Aquat Org 71:141-148

Miller DL, Rajeev S, Gray MJ, Baldwin CA (2007) Frog virus 3 infection, cultured American bullfrogs. Emerg Infect Dis 13:342-343

Miller DL, Rajeev S, Brookins M, Cook J, Whittington L, Baldwin CA (2008) Concurrent infection with ranavirus, Batrachochytrium dendrobatidis, and Aeromonas in a captive anuran colony. J Zoo Wildl Med 39:445-449

Miller DL, Gray MJ, Rajeev S, Schmutzer AC, Burton EC, Merrill A, Baldwin CA (2009) Pathological findings in larval and juvenile anurans inhabiting farm ponds in Tennessee, USA. J Wildl Dis 45:314-324

Miller D, Gray M, Storfer A (2011) Ecopathology of ranaviruses infecting amphibians. Viruses 3:2351-2373

Milton JS, Arnold JC (1995) Introduction to probability and statistics. McGraw-Hill, Boston, MA

Morales HD, Abramowitz L, Gertz J, Sowa J, Vogel A, Robert J (2010) Innate immune responses and permissiveness to ranavirus infection of peritoneal leukocytes in the frog Xenopus leavis. J Virol 84:4912-4922

Pallister J, Gould A, Harrison D, Hyatt A, Jancovich J, Heine H (2007) Development of real-time PCR assays for the detection and differentiation of Australian and European ranaviruses. J Fish Dis 30:427-438

Pessier AP, Mendelson JR (eds) (2010) A manual for control

Editorial responsibility: V. Gregory Chinchar,

Jackson, Mississippi, USA of infectious diseases in amphibian survival assurance colonies and reintroduction programs. IUCN/SSC Conservation Breeding Specialist Group, Apple Valley, MN

> Picco AM, Brunner JL, Collins JP (2007) Susceptibility of the endangered California tiger salamander, Ambystoma californiense, to ranavirus infection. J Wildl Dis 43: 286-290

Robert J, Morales H, Buck W, Cohen N, Marr S, Gantress J (2005) Adaptive immunity and histopathology in Frog virus 3-infected Xenopus. Virology 332:667-675

Schloegel LM, Picco AM, Kilpatrick AM, Davies AJ, Hyatt AD, Daszak P (2009) Magnitude of the US trade in amphibians and presence of Batrachochytrium dendrobatidis and ranavirus infection in imported North American bullfrogs (Rana catesbeiana). Biol Conserv 142:1420-1426

> St-Amour V, Lesbarrères D (2007) Genetic evidence of ranavirus in toe clips: an alternative to lethal sampling methods. Conserv Genet 8:1247-1250

Stokes ME, Davis CS, Kock GG (2000) Categorical data analysis using the SAS ${ }^{\circledR}$ system. SAS Institute, Cary, NC

Stuart SN, Chanson JS, Cox NA, Young BE, Rodrigues ASL, Fischman DL, Waller RW (2004) Status and trends of amphibian declines and extinctions worldwide. Science 306:1783-1786

Wake DB, Vredenburg VT (2008) Are we in the midst of the sixth mass extinction? A view from the world of amphibians. Proc Natl Acad Sci USA 105:11466-11473

Submitted: June 16, 2011; Accepted: January 3, 2012

Proofs received from author(s): April 12, 2012 